\title{
Equidad y Desarrollo
}

January 2018

\section{Comportamiento del microcrédito en Colombia durante el periodo 2010-2014: exploración desde la perspectiva de la Escuela de Ohio y del Grameen Bank}

Ómar Villamizar Jímenez

Universidad de La Salle, Bogotá, omar.villamizar@outlook.com

Julio César Ducón Salas

Universidad de La Salle, Bogotá, jcducon@unisalle.edu.co

Follow this and additional works at: https://ciencia.lasalle.edu.co/eq

\section{Citación recomendada}

Villamizar Jímenez, Ó., y J.C. Ducón Salas (2018). Comportamiento del microcrédito en Colombia durante el periodo 2010-2014: exploración desde la perspectiva de la Escuela de Ohio y del Grameen Bank. Equidad y Desarrollo, (30), 221-244. https://doi.org/10.19052/ed.4175

This Artículo de Investigación is brought to you for free and open access by the Revistas científicas at Ciencia Unisalle. It has been accepted for inclusion in Equidad y Desarrollo by an authorized editor of Ciencia Unisalle. For more information, please contact ciencia@lasalle.edu.co. 


\title{
Comportamiento del microcrédito en Colombia durante el periodo 2010-2014: exploración desde la perspectiva de la Escuela de Ohio y del Grameen Bank*
}

\author{
Ómar Villamizar Jiménez ${ }^{* *}$ \\ Julio César Ducón Salas***
}

\section{Palabras clave}

Microcrédito, microfinanzas, bancarización, pobreza, servicios

\section{Clasificación JEL}

G21, G20, G29

\section{Resumen}

Este artículo tiene como objetivo presentar una descripción del comportamiento que tuvo el microcrédito en Colombia durante el periodo 2010-2014; se realizó un análisis exploratorio basado en los conceptos de la Escuela de Ohio y el Grameen Bank. Las unidades representativas propuestas para la realización del estudio se fundamentaron en la cuenta de cartera que durante el periodo analizado reportaron las entidades que, en el mercado colombiano, ofrecen este tipo de créditos. Como producto del análisis se encontró que la generación de oportunidades y el acceso a servicios financieros se relacionan con las políticas de bancarización implementadas por los últimos gobiernos con el fin de auxiliar a los microempresarios colombianos, lo cual está en mayor sintonía con los principios de la Escuela de Ohio.

Cómo citar este artículo: Villamizar Jiménez, O. y Ducón Salas, J. C. (2018). Comportamiento del microcrédito en Colombia durante el periodo 2010-2014: exploración desde la perspectiva de la Escuela de Ohio y del Grameen Bank, Equidad y Desarrollo, (30), 221-244. doi: http://dx.doi. org/10.19052/ed.4175

Fecha de recepción: 5 de julio de 2017 • Fecha de aceptación: 2 de octubre de 2017

* Artículo derivado del proyecto de investigación "Factores de riesgo y cambio organizacional Análisis del tejido empresarial de la ciudad de Bogotá para el periodo 2004-2014”.

** Administrador de empresas de la Universidad de La Salle, Colombia. Especialista en Proyectos del Banco Procredit. Correo electrónico: omar.villamizar@outlook.com

*** Magíster en Desarrollo Educativo y Social del Centro Internacional de Educación y Desarrollo (Cinde). Especialista en Proyectos de Desarrollo de la Escuela Superior de Administración (ESAP) y administrador financiero de la Fundación Universitaria Agraria de Colombia (Uniagraria). Docente investigador de tiempo completo de la Facultad de Ciencias Administrativas y Contables de la Universidad de La Salle, Colombia. Integrante del grupo de investigación en Gestión, Administración y Organizaciones $(\mathrm{GAO})$, clasificación C en Colciencias. Correo electrónico: jcducon@unisalle.edu.co 


\section{Microcredit behavior in Colombia during the period 2010-2014: Exploration from the perspective of the Ohio School and the Grameen Bank}

Microcredit, microfinance, banking, poverty, services

\section{Palavras chave}

Microcrédito, micro finanças, bancarização, pobreza, serviços

\begin{abstract}
This article aims to describe microcredit behavior in Colombia during the period 2010-2014, performing an exploratory analysis based on the concepts of the Ohio School and the Grameen Bank. The representative units proposed for the study are based on portfolio reports from the analyzed period that were presented by entities that offer this type of loans in the Colombian market. The analysis found that the generation of opportunities and access to financial services are related to banking policies implemented by the last governments in order to help Colombian micro-entrepreneurs, which is more in tune with the principles of the Ohio School.
\end{abstract}

\section{Comportamento do microcrédito na Colômbia durante o período 2010-2014: exploração desde a perspectiva da Escola de Ohio e do Grameem Bank}

\section{Resumo}

O objetivo deste artigo é apresentar uma descrição do comportamento do microcrédito na Colômbia durante o período 2010-2014; fez-se uma análise exploratório baseada nos conceitos da Escola de Ohio e o Grameem Bank. As unidades representativas propostas para a realização do estudo fundamentaram-se na conta de carteira que durante o período analisado foram reportadas pelas entidades que, no mercado colombiano, oferecem este tipo de empréstimos. Como produto da análise constatou-se que a geração de oportunidades e o acesso aos serviços financeiros estão relacionados com as políticas de bancarização implementadas pelos últimos governos com o fim de auxiliar aos micro empresários colombianos, o que mantém mais sintonia com os princípios da Escola de Ohio. 
La pobreza no la crea la gente pobre. Esta es producto del sistema que hemos creado, por ende hay que cambiar los modelos y conceptos rígidos de nuestra sociedad.

Muhammad Yunus

\section{Introducción}

Los acelerados cambios ocurridos en las últimas décadas han ocasionado que diferentes sectores y actividades que componen la economía colombiana adopten medidas no solamente como respuesta a las amenazas surgidas en su entorno; también, se ha identificado la necesidad de responder a la dinámica del mundo actual. Ejemplo de ello es la reingeniería realizada en el sistema financiero colombiano, la cual se llevó a cabo a principios del presente siglo con el fin de crear una red de seguridad al sistema, lo que derivó en la adopción de reformas direccionadas a restablecer la confianza de los ahorradores y evitar reincidir en coyunturas críticas, como las que afrontó el sector a finales del siglo XX, como lo exponen Rojas y González (citados en Ocampo, 2015).

Estas medidas, sumadas al acceso al mercado externo de capitales, permitieron que a partir de 2010 se generara una fuerte aceleración de la cartera, que, en materia de profundización medida por activos, acumuló 21 puntos porcentuales del producto interno bruto (PIB) en solo 5 años; esta expansión estuvo acompañada de un fuerte crecimiento en los niveles de endeudamiento externo, lo que propició que Colombia hiciera parte del grupo de economías latinoamericanas con acceso favorable al mercado internacional de capitales (Ocampo, 2015).

Como se mencionó, al iniciar el siglo XX, el Estado colombiano empezó a establecer una serie de leyes, normas y regulaciones, como se detalla en la tabla 1 , con el fin de incentivar la colocación de microcréditos, brindar garantías a las diferentes entidades financieras y estimular la oferta de créditos destinados a capital de trabajo o activos fijos, para así promover el desarrollo de las empresas. 
Tabla 1. Normatividad relacionada con el microcrédito

\begin{tabular}{|c|c|c|}
\hline Regulación & Objetivo & Descripción \\
\hline Ley 590 de 2000 nivel nacional & $\begin{array}{l}\text { Establecer las disposiciones } \\
\text { para promover el desarrollo de } \\
\text { las micro, pequeñas y medianas } \\
\text { empresas. }\end{array}$ & $\begin{array}{l}\text { Creó el Consejo Superior de } \\
\text { Microempresa y definió la } \\
\text { microempresa: } \\
\text { a) planta de personal no } \\
\text { superior a los diez (10) } \\
\text { trabajadores; b) activos totales } \\
\text { por valor inferior a quinientos } \\
\text { uno (50l) salarios mínimos } \\
\text { legales vigentes (SMLV). }\end{array}$ \\
\hline $\begin{array}{l}\text { Resolución } 01 \text { del } 7 \text { de marzo } \\
\text { de } 2007\end{array}$ & $\begin{array}{l}\text { Fijar la tasa máxima a } \\
\text { cobrar por concepto de } \\
\text { honorarios y comisiones en los } \\
\text { microcréditos. }\end{array}$ & $\begin{array}{l}\text { - Para créditos inferiores a } \\
\text { cuatro (4) SMLV, los hono- } \\
\text { rarios y comisiones de que } \\
\text { trata el artículo } 39 \text { de la Ley } \\
590 \text { de } 2000 \text { no podrán su- } \\
\text { perar la tarifa de } 7,5 \% \text { anual } \\
\text { sobre saldo del crédito. } \\
\text { Para créditos iguales o supe- } \\
\text { riores a cuatro (4) SMLV, los } \\
\text { honorarios y las comisiones } \\
\text { de que trata el artículo } 39 \\
\text { de la Ley } 590 \text { de } 2000 \text { no } \\
\text { podrán superar la tarifa de } \\
4,5 \% \text { anual sobre saldo del } \\
\text { crédito. }\end{array}$ \\
\hline $\begin{array}{l}\text { Circular externa } 50 \text { de } 2001 \text { de } \\
\text { la Superintendencia Financiera }\end{array}$ & $\begin{array}{l}\text { Establecer el microcrédito } \\
\text { como una nueva modalidad de } \\
\text { crédito en el plan únicico de } \\
\text { cuentas (PUC). }\end{array}$ & $\begin{array}{l}\text { Se crea la nueva modalidad de } \\
\text { crédito para el registro contable } \\
\text { de todas las operaciones o } \\
\text { transacciones bajo la modalidad } \\
\text { de microcrédito. }\end{array}$ \\
\hline Ley 795 de 2003 & $\begin{array}{l}\text { Ajustar algunas normas del } \\
\text { Estatuto Orgánico del Sistema } \\
\text { Financiero y se dictan otras } \\
\text { disposiciones. }\end{array}$ & $\begin{array}{l}\text { - Autorizó recibir créditos de } \\
\text { otros establecimientos de } \\
\text { crédito para la realización } \\
\text { de operaciones de micro- } \\
\text { crédito. } \\
\text { Estableció el microcrédito } \\
\text { inmobiliario. }\end{array}$ \\
\hline Decreto 3078 de 2006 & $\begin{array}{l}\text { Crear el programa de inversión } \\
\text { denominado Banca de } \\
\text { Oportunidades. }\end{array}$ & $\begin{array}{l}\text { Promover y fomentar el acceso } \\
\text { al crédito y los demás servicios } \\
\text { financieros a las familias de } \\
\text { menores ingresos, micro, } \\
\text { pequeñas y medianas empresas } \\
\text { y emprendedores. }\end{array}$ \\
\hline
\end{tabular}

Fuente: elaboración propia con base en las regulaciones citadas. 
Con estas medidas, esta modalidad de crédito ${ }^{1}$ se ha convertido en un atractivo para diferentes entidades: bancarias, cooperativas, organizaciones no gubernamentales (ONG) y diferentes compañías de financiamiento; como se evidencia en el informe Perspectivas de la cartera de crédito (Superintendencia Financiera de Colombia, 2014), el microcrédito ha presentado en los bancos una tendencia creciente en profundización financiera ${ }^{2}$ del $0,8 \%$, en 2010, al 1,19\%, en marzo de 2014, en razón a su dinámica y a la población que está dirigido, aún hay mucho potencial de crecimiento.

Dadas las condiciones de bancarización generadas a partir del impulso que el microcrédito ha tenido tanto para microempresarios como para personas naturales, es relevante analizar el comportamiento que tuvo este tipo de crédito en Colombia durante el periodo 2010-2014, haciendo énfasis en la cartera de diferentes tipos de entidades, principalmente las instituciones especializadas, ${ }^{3}$ la cuales han aportado significativamente a este segmento de la población.

\section{Referentes conceptuales}

Debido a la desigualdad y pobreza que, en términos monetarios, continúan caracterizando a muchas sociedades, diversas entidades que operan en el marco del sistema financiero han ampliado su portafolio de servicios y han implementado diferentes tipos de créditos en los que la capacidad de pago no es el único ni el factor más relevante para el acceso efectivo al crédito, ya que su propósito radica en el aumento de la cobertura en términos de acceso poblacional. Este tipo de colocaciones, en los contextos nacional e internacional, se han gestado como una posibilidad de inclusión y disminución de la pobreza, lo cual, de acuerdo con

1 Para propósitos de información, evaluación del riesgo crediticio, aplicación de normas contables y constitución de provisiones, entre otras, la cartera de créditos se clasifica en las siguientes cuatro modalidades: vivienda, consumo, microcrédito y comercial (Superintendencia Financiera de Colombia, 2002).

2 Este indicador se mide en relación con la cartera como proporción del producto interno bruto (PIB). Supuestos: crecimiento del PIB nominal 6,79\%. Inflación: 1,90\%. PIB real: 4,8\%. Rango medio de estimaciones del Banco de la República.

3 Las instituciones especializadas son las que realizan operaciones de tipo específico: bancos de depósito y ahorro, sociedades financieras, sociedades de crédito hipotecario, instituciones de capitalización, etc. (Ramírez, 2001). 
Gutiérrez (2006), fundamenta conceptualmente el microcrédito y las microfinanzas, lo que da origen a dos corrientes: la Escuela de Ohio y la Escuela del Grameen Bank.

226 La Escuela de Ohio surgió en 1973; un grupo de economistas de la Universidad del Estado de Ohio aportaron para mejorar las deficiencias que presentaban los mercados de crédito, los principios y aportes que los destacarían se dan a conocer a continuación.

Según los planteamientos de González-Vega (citado en Gutiérrez, 2006), "el crédito no puede crear un mercado inexistente, [...]. No convierte en empresario al que no tiene capacidades para hacerlo" (p. 177). Adams y Von Pischke (citados en Gutiérrez, 2006) afirman que "la 'deuda', con todas sus connotaciones negativas, oponiendo al 'crédito', no constituye una herramienta efectiva para ayudar a las personas a mejorar su condición económica. La imposición de más deuda a los pobres no es una estrategia adecuada de desarrollo" (p. 177); es decir, los créditos deben ser otorgados a las personas que tengan necesidades y un plan de inversión definido, cubriendo necesidades existentes del mercado.

Por su parte, Adams y Von Pischke (citados en Gutiérrez, 2006) mencionan que "la falta de créditos formales no es el problema más acuciante que afrontan los pobres" (p. 178). Este planteamiento nos afirma que los créditos no son la solución para todos los problemas, por el contrario, el otorgar un crédito a una persona que no tiene las habilidades empresariales causará más dificultades.

Hospes (citado en Gutiérrez, 2006) afirma que "los bajos tipos de interés crean una demanda artificial entre los más acomodados. [...] Es más barato conceder un préstamo grande que muchos pequeños" (p. 178).

Después de esbozar los principios de esta escuela, se puede concluir que no se deben crear demandas inexistentes en los mercados, el equilibrio general, deben acceder a los créditos quienes tengan capacidades empresariales, los créditos no solucionan todos los problemas.

La segunda escuela de la que se expondrán sus principios es la propuesta por Muhammad Yunus, economista, emprendedor social, galardonado con el Nobel de Paz y creador y fundador del Banco Grameen. Yunus (2008) dice: "en 1974, me di cuenta de lo difícil que resultaba enseñar elegantes teorías económicas en las aulas universitarias en el contexto de la terrible hambruna que estaba padeciendo Bangladesh" (p. 12). Se puede evidenciar cómo sus ideales se dieron en un entorno lleno de hambre, pobreza y diferentes problemas sociales, lo que lo motivó a ayudar a la gente que lo rodeaba, sin importar la cantidad de personas que lograra ayudar; 
"fue entonces cuando decidí crear un banco separado para las personas pobres y, en 1983, la idea se hizo finalmente realidad lo llamé Banco Grameen (es decir, Banco 'Rural' o ‘De los pueblos')” (Yunus, 2008, p. 13).

El objetivo central de la escuela del Grameen Bank es crear oportunidades para los más pobres y garantizarles el acceso a servicios financieros, bajo los siguientes lineamientos:

1. Gran parte del capital social es propiedad de sus prestatarios.

2. La distribución de la renta en el mundo no es equitativa, la escuela del Grameen Bank propone la generación de estrategias que permitan una mejor distribución de recursos.

3. Está encaminado a la prestación de servicios financieros exclusivamente a los pobres, los créditos son otorgados sin garantía real, los prestatarios se respaldan solidariamente.

Esta escuela ha logrado tener un reconocimiento en el mundo, por el establecimiento de créditos a pequeña escala, por su lucha contra la desigualdad, la pobreza y las oportunidades limitadas; se convirtió en un referente en muchos países, en la contribución al desarrollo de economías justas para los más pobres.

Según el Consultative Group to Assist the Poor (CGAP) (s. f.), hace algunas décadas el término "microfinanzas" estaba vinculado estrechamente con microcréditos - préstamos muy pequeños-; sin embargo, este se ha ampliado y ha incluido una variedad de servicios (ahorros, seguros, pagos, remesas, entre otros) y personas de bajos ingresos, lo que promueve el acceso a servicios financieros de calidad.

Por esto, en la actualidad, las entidades ofrecen una variedad de servicios que no solo se limitan al otorgamiento de créditos, también buscan desarrollar servicios ajustados a las necesidades de sus clientes, que a su vez permiten a las entidades generar ingresos por concepto de comisiones e ingresos financieros.

El modelo de microfinanzas en Colombia ha obtenido avances en las alternativas de financiación, y ha estado apoyado por la prestación de diversos servicios financieros; en el artículo, se denota la importancia de los microcréditos, por medio de la cartera y el número de los microempresarios que las entidades financieras han atendido bajo esta modalidad de crédito durante el periodo 2010-2104; para esto, se describe el proceso para llegar al objetivo. 


\section{Metodología}

La metodología se basó, principalmente, en un enfoque cuantitativo de tipo descriptivo; se consultaron fuentes de información de tipo secundario, como registros en libros, documentos e informes históricos consignados en la Superintendencia Financiera y la Banca de Oportunidades, así como otras entidades que desarrollan este tipo de actividad.

Dado que el objetivo propuesto es conocer el comportamiento del microcrédito en el contexto colombiano, se plantearon, inicialmente, las siguientes unidades de análisis básicas: saldo de cartera, monto de colocación (clasificado en dos: segmento 1 , que indica la colocación menor o igual a 25 salarios mínimos legales vigentes (SMLV), y segmento 2, con un rango entre 25 SMLV y 120 SMLV), número de clientes y tasas de interés (bancario y de usura), con el fin de describir su comportamiento en el periodo de tiempo planteado (tabla 2).

Tabla 2. Variables de análisis

\begin{tabular}{|c|l|}
\hline \multirow{2}{*}{ Monto de cartera } & $\begin{array}{l}\text { Segmento } 1 \text { que indica la colocación menor o igual a 25 SMLV. } \\
\text { Segmento } 2 \text { con un rango entre 25 SMLV y } 120 \text { SMLV. } \\
\text { Segmento } 1 \text { que indica la colocación menor o igual a 25 SMLV. } \\
\text { Tasas de interés } \\
\text { Segmento } 2 \text { con un rango entre 25 SMLV y } 120 \text { SMLV. } \\
\text { Bancario corriente. } \\
\text { Usura. }\end{array}$ \\
\hline
\end{tabular}

Fuente: elaboración propia.

Para el análisis de los datos obtenidos, se llevó a cabo, inicialmente, una interpretación apoyada en los datos a lo largo del horizonte del tiempo estudiado. Luego, se analizaron, descriptivamente, con base en los índices de correlación y determinación, las relaciones entre estas variables (tabla 3). 
Tabla 3. Índice de correlación y determinación

\begin{tabular}{|c|c|c|c|}
\hline Índice & Fórmula & Variable explicativa (X) & Variable explicada (Y) \\
\hline $\begin{array}{l}\text { Índice de } \\
\text { correlación }\end{array}$ & $r=\frac{S_{X Y}}{S_{X} S_{Y}}$ & $\begin{array}{l}\text { Tasas de interés } \\
\text { bancario y de usura }\end{array}$ & $\begin{array}{l}\text { Bancarización } \\
\text { Número de clientes } \\
\text { Montos de colocación }\end{array}$ \\
\hline $\begin{array}{l}\text { Índice de } \\
\text { determinación }\end{array}$ & $\begin{array}{l}\mathrm{r}^{2}=\frac{\text { variación explicada }}{\text { variación total }} \\
\mathrm{r}^{2}=\frac{\sum(\hat{\mathrm{Y}}-\overline{\mathrm{Y}})^{2}}{\sum\left(\mathrm{Y}_{\mathrm{i}}-\overline{\mathrm{Y}}\right)^{2}}\end{array}$ & $\begin{array}{l}\text { Tasas de interés } \\
\text { bancario y de usura }\end{array}$ & $\begin{array}{l}\text { Bancarización } \\
\text { Número de clientes } \\
\text { Montos de colocación }\end{array}$ \\
\hline
\end{tabular}

Fuente: elaboración propia.

Finalmente, para el planteamiento de la discusión, se hace una relación entre las características de las escuelas descritas (Ohio y Grameen Bank) y los resultados obtenidos, lo que permite conocer cuáles son los principios del microcrédito más aplicados en el contexto colombiano.

\section{Resultados}

En el marco del sistema financiero colombiano, la colocación de microcréditos se realiza, principalmente, por la operación de entidades, como bancos, cooperativas y compañías de financiamiento, entre otras; las cuales, de acuerdo con la Banca de Oportunidades (2015), permiten conocer, a partir de la cartera de estas entidades, que los bancos tienen un $69 \%$ de la colocación, seguidos de ONG autorizadas con una participación de más del $18 \%$ y los demás tipos de entidades tienen una participación inferior al 10\% (figura 1).

La gran participación de los bancos está dada principalmente por cambios ocurridos en el sector financiero, ya que, al volver los ojos a este mercado, encuentran un segmento rentable que demanda múltiples servicios y productos, los cuales estaban siendo ofertados principalmente por ONG, fondos de empleados, así como otras entidades de carácter solidario que han colocado recursos principalmente en pymes. Lo anterior ha dado como resultado que las entidades financieras se reorganicen y creen grupos especializados en la materia con el fin de atender y captar nuevos clientes, incluso saliendo de las oficinas para acercarse a estos llevando a 
Figura 1. Participación por tipo de entidad en la cartera de microcréditos en Colombia, 2014

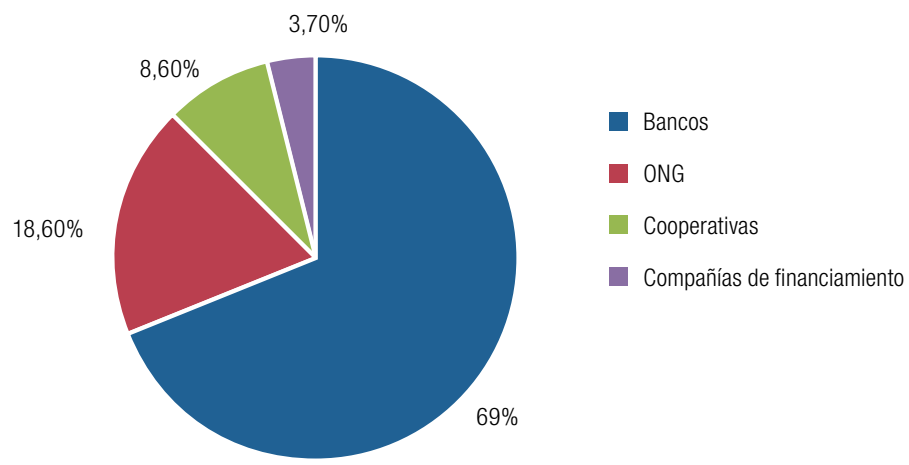

Fuente: elaboración propia con base en datos de la Banca de Oportunidades (2015).

cabo actividades de colocación y captación por medio de una oferta integral de servicios, aspecto que marca precisamente la diferencia en la participación en este mercado. Según Navajas y Tejerina:

[...] el desarrollo de instituciones orientadas hacia el acceso a servicios financieros por parte de la población con menos recursos surge en estos países como una iniciativa de organizaciones no gubernamentales (ONG) y entidades multilaterales [...]. A partir del desarrollo de una tecnología crediticia adaptada a las necesidades de los microempresarios. (Citados en Banco de la República, 2010, p. 3)

Sin embargo, según el reporte de la Situación actual del microcréditoen Colombia, delBancodela República(2014), el mercadodemicrocréditoylasentidadesreguladas son los principales indicadores y factores que impiden otorgar préstamos; se destaca la capacidad de pago con el $21 \%$, como el primer factor negativo; el nivel de deuda del cliente es superior a su capacidad de pago, con un 19\%; deudas con más de tres entidades, con el 18\%; historial crediticio, con el 13\%; los demás factores, como falta de interés por cumplir sus obligaciones, reestructuración de préstamos, falta de información financiera y actividad económica, cada uno con menos del $5 \%$ (figura 2). 
Figura 2. Principales factores que impiden el otorgamiento de microcréditos en Colombia, 2014

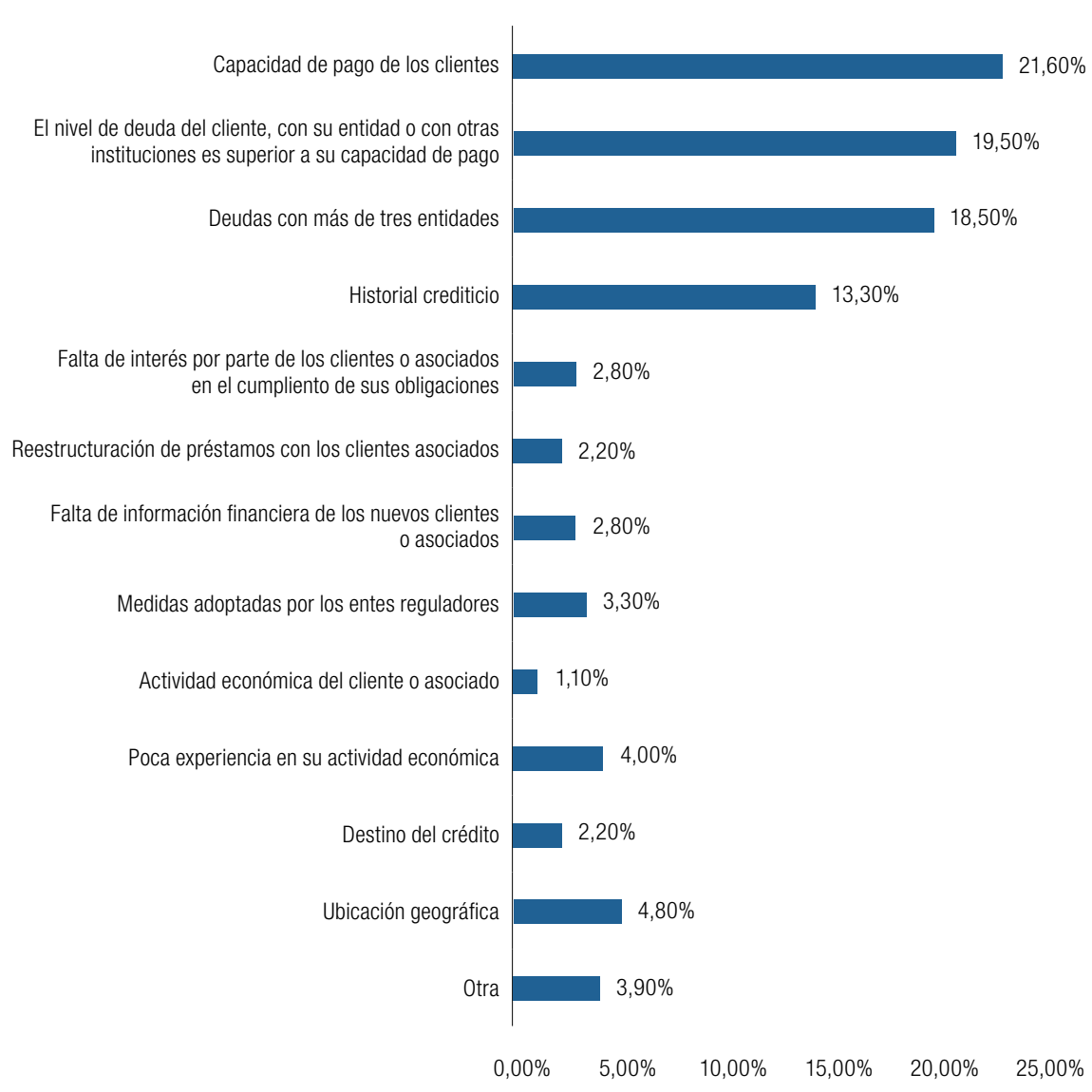

Fuente: Banco de la República (2014).

Las diferentes entidades financieras buscan un conocimiento del cliente; un factor determinante en el momento de una aprobación de crédito es el nivel de deuda, un elevado endeudamiento aumenta el riesgo y la probabilidad de incumplimiento de la obligación, y tener varias obligaciones vigentes con diferentes entidades sin tener la capacidad de pago para responder a sus obligaciones puede llegar a un nivel de sobreendeudamiento. 
Para acceder a un crédito del segmento de microcrédito, convergen diversas variables, desde la parte cualitativa, como la edad, la antigüedad en el negocio, el cumpliento de las normas y leyes de acuerdo con la actividad económica, el soporte documental de los ingresos y la ubicación geográfica; hasta la parte cuantitativa, como respaldo patrimonial, capacidad de pago, capacidad de endeudamiento y solvencia.

De acuerdo con la Banca de Oportunidades (2014), en los últimos 5 años, como se detalla en la figura 3, el saldo de la cartera de microcrédito pasó de 4,6 billones en diciembre de 2010 a 8,4 billones en diciembre de 2014; en este periodo, se evidencia un comportamiento de crecimiento del $83 \%$, lo que ratifica el interés de las entidades financieras en la colocación de este tipo de créditos en el mercado, que a su vez los microempresarios utilizan en capital de trabajo, adquisición de activos fijos para sus unidades productivas o compra de cartera.

Figura 3. Crecimiento de la cartera de microcréditos 2010-2014 en billones de pesos

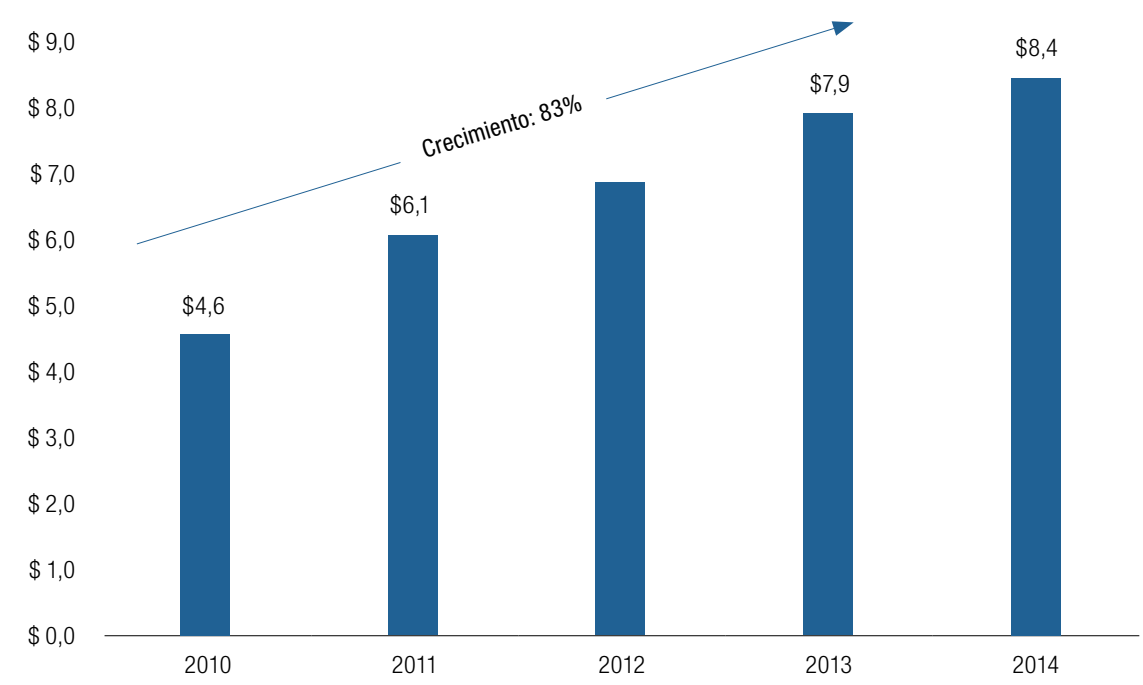

Fuente: elaboración propia con base en datos de la Banca de Oportunidades (2010-2014).

La Resolución 01 del 7 de marzo de 2007, del Consejo Superior de la Microempresa, indica que la cartera de microcréditos se encuentra segmentada por montos 
inferiores a $25 \mathrm{SMLV}$ y entre $25 \mathrm{SMLV}$ a $120 \mathrm{SMLV}$, para el periodo 2010-2014; de acuerdo con la segmentación citada, cada año representó un crecimiento del 79 y $87 \%$, respectivamente; como se detalla en la figura 4 , las entidades concentraron la cartera, principalmente, en operaciones inferiores a $25 \mathrm{SMLV}$, con un incremento constante, representado en una cartera total de 6961 billones de pesos al cierre de 2014. Los montos montos superiores a 25 SMLV cerraron en 1509 billones de pesos, lo que indica un aumento en la capacidad de pago y acceso a obligaciones crediticias de montos más representativos.

Figura 4. Cartera de microcrédito por segmento 2014 en billones de pesos

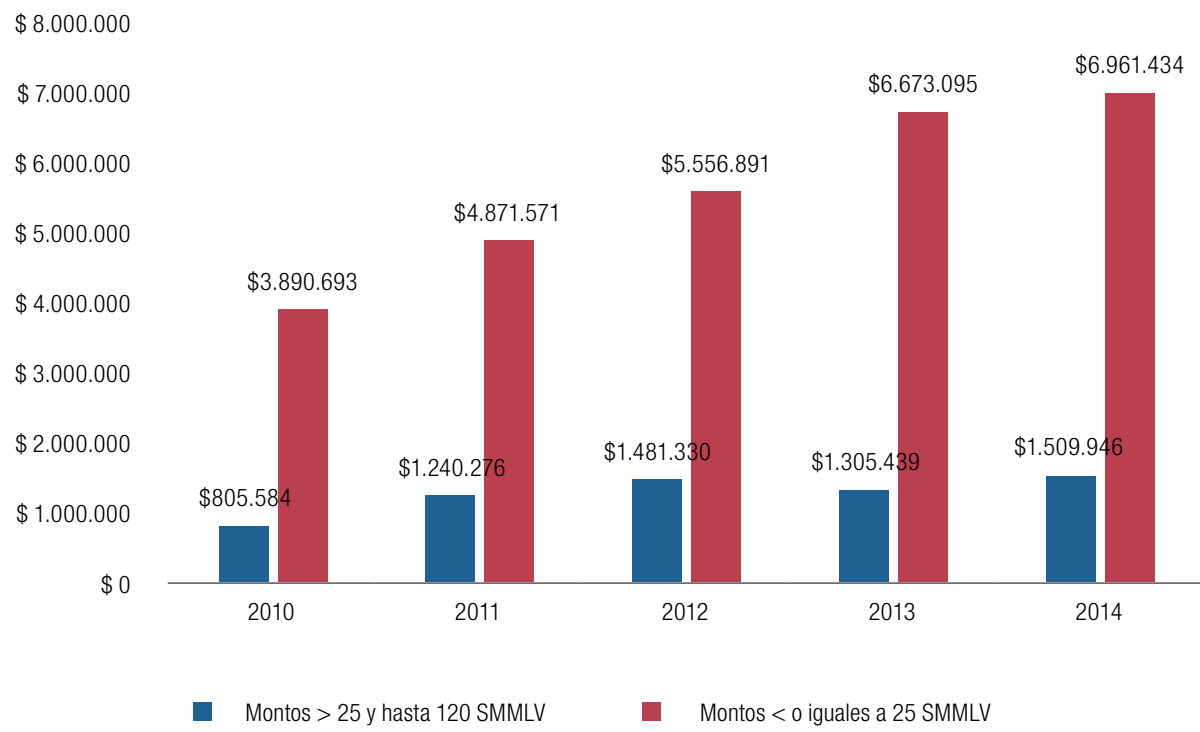

Fuente: elaboración propia con base en datos de Banca de Oportunidades (2014).

Sin embargo, en la composición de la cartera total, los microcréditos inferiores a $25 \mathrm{SMLV}$ representaron un $82 \%$, frente a un $18 \%$ en las operaciones, hasta los 120 SMLV en diciembre de 2014, la participación considerablemente en montos inferiores fue de $25 \mathrm{SMLV}$, como se detalla en la figura 5; esto ratifica que el mercado de microempresarios colombianos solicitó préstamos bajo esta modalidad, los cuales fueron otorgados por entidades financieras interesadas en crecer en este segmento. 
Figura 5. Composición de la cartera por segmento 2010-2014

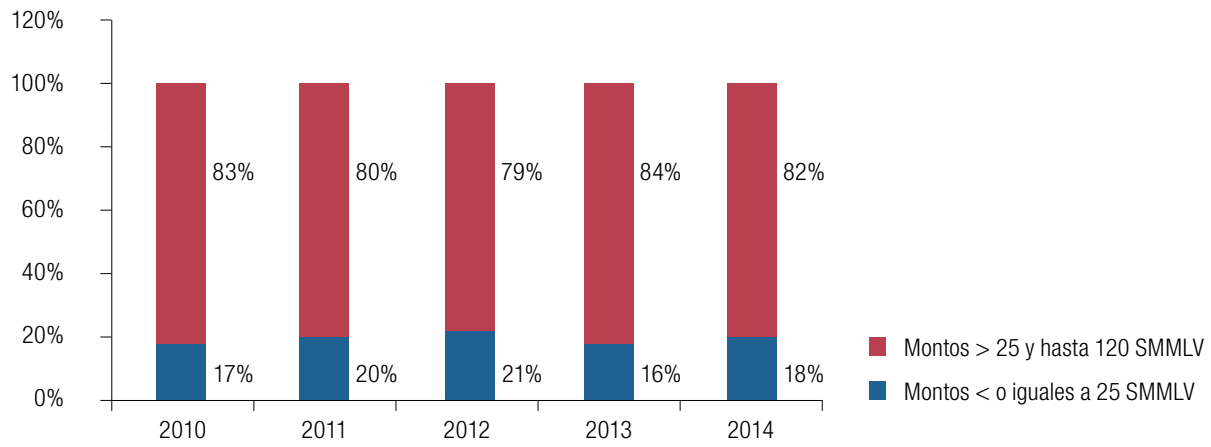

Fuente: elaboración propia con base en datos de la Banca de Oportunidades.

En la figura 6, se aprecia el comportamiento en número de clientes para cada uno de los años; los clientes atendidos con créditos inferiores a 25 SMLV superaron las 2.500.000 personas; por otro lado, con una contribución muy inferior, los microcréditos de hasta $120 \mathrm{SMLV}$ no superaron las 83.000 operaciones al cierre de diciebre de 2014.

Figura 6. Comportamiento del microcrédito en número de clientes 2010-2014

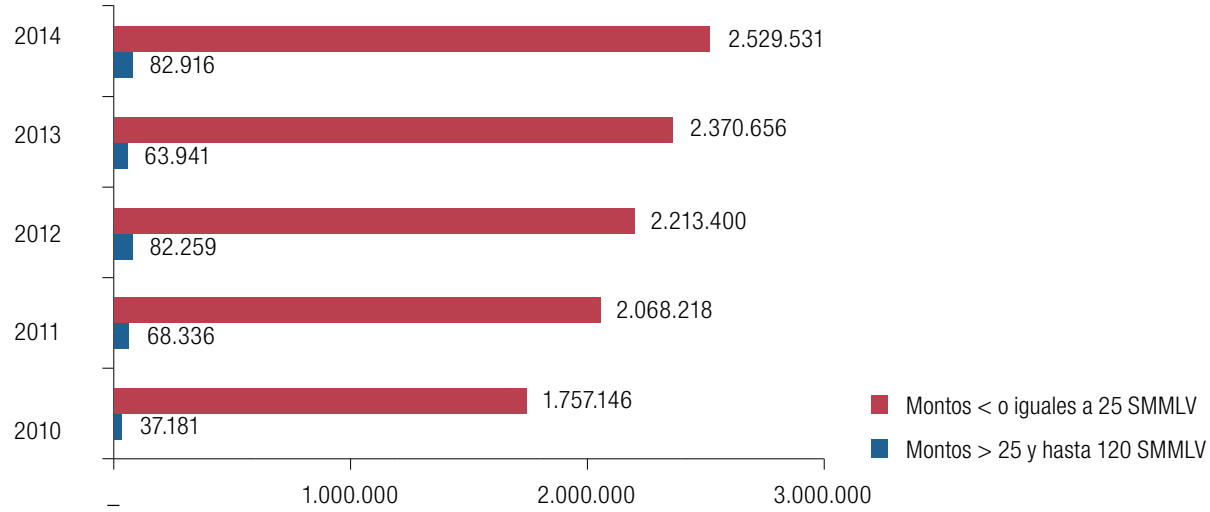

Fuente: elaboración propia con base en datos de la Banca de las Oportunidades (2014a). 
Con respecto a la tasa de interés, se encuentra, durante el periodo estudiado, que el interés bancario corriente - el cual consiste en la tasa efectiva anual promedio (ponderada por el monto de los desembolsos del periodo), que es cobrada en el marco del sistema financiero colombiano por aquellas entidades que son vigiladas por la Superintendencia Financiera - y la tasa de usura aumentaron de 2010 a 2014, en 41,56\% (figura 7). Esta última se entiende como el límite máximo con el que un particular o una entidad financiera puede cobrar por intereses sobre un préstamo, y es superior en la mitad a la tasa de interés corriente.

Figura 7. Comportamiento del interés bancario y tasa de usura 2010-2014

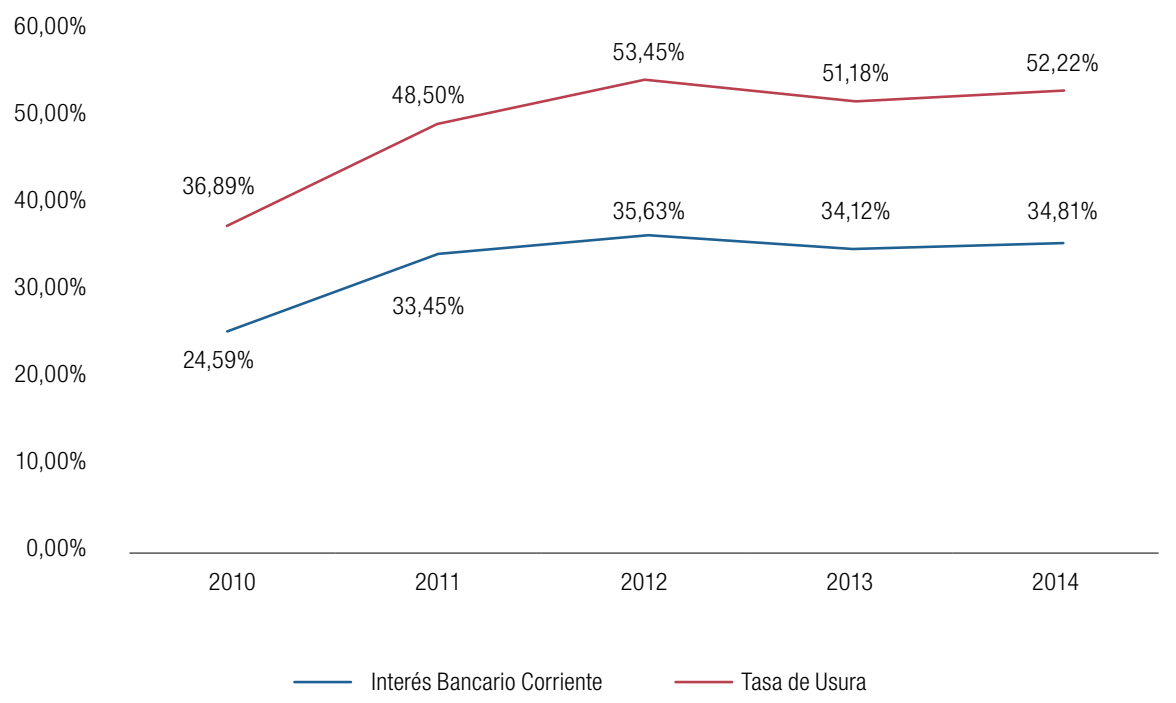

Fuente: Asomicrofinanzas (2014).

Teniendo en cuenta que las tasas de interés tienen un papel relevante en el crecimiento de la economía por su incidencia en el consumo y el efecto inflacionario que pueden generar, se evidencia, en el comportamiento creciente presentado por estas, que durante el periodo 2010-2014 se produjeron, principalmente, como resultado de las políticas antiinflacionarias y no por estímulo al ahorro y la inversión de nacionales. 
Los anteriores datos, en general, evidencian que el microcrédito en Colombia tuvo, durante el periodo analizado, un comportamiento creciente en cuanto a la colocación de recursos en el mercado, que, como se vio en la figura 3, aumentó en un $83 \%$, cifra que es bastante significativa si se tiene en cuenta que los datos de bancarización tuvieron un comportamiento que creció en un 16,94\%, debido a la ampliación de la oferta de servicios financieros con carácter incluyente. Este avance se dio, especialmente, como resultado del diseño de productos de trámite simplificado, una mayor protección al consumidor, los incentivos para la oferta de microcréditos y seguros y la expansión de la banca móvil (Cano, 2014).

En este orden de ideas, la correlación entre el interés bancario corriente y la bancarización permite inferir que existe una relación lineal positiva entre estas dos variables $(73 \%)$. Sin embargo, si se tiene en cuenta que, por definición, la bancarización es un proceso económico de "inclusión social" al sistema financiero, que se produce a partir de una serie de políticas e incentivos aplicados con el fin de motivar u obligar a la gente a tener algún servicio financiero, se deduce por medio de su índice de determinación que la tasa de interés no es lo suficientemente explicativa de este proceso $(53,29 \%)$, lo cual sí sucede con respecto a los montos de colocación 93,06 y 95,54\% (tabla 4); lo anterior demuestra que, a pesar de haberse incrementado el cobro de intereses, se aumentó la demanda de microcréditos en ambos segmentos, en mayor medida en los montos menores o iguales a $25 \mathrm{SMLV}$, es decir, se demandaron más recursos crediticios empero el comportamiento progresivo del interés.

Tabla 4. Datos históricos 2010-2014 relacionados con el microcrédito

\begin{tabular}{|c|c|c|c|c|c|}
\hline & $\begin{array}{c}\text { Interés } \\
\text { bancario } \\
\text { corriente (\%) }\end{array}$ & $\begin{array}{c}\text { Tasa de usura } \\
(\%)\end{array}$ & $\begin{array}{c}\text { Bancarización } \\
(\%)\end{array}$ & $\begin{array}{c}\text { Colocación } \\
\text { montos menores } \\
\text { a 25 y hasta 120 } \\
\text { SMLV (\$) }\end{array}$ & $\begin{array}{c}\text { Colocación } \\
\text { montos mayores } \\
\text { o iguales a 25 } \\
\text { SMLV } \\
(\$)\end{array}$ \\
\hline 2010 & 24,59 & 36,89 & 62,00 & 805.584 & 3.890 .693 \\
2011 & 33,45 & 48,50 & 64,90 & 1.240 .276 & 4.871 .571 \\
2012 & 35,63 & 53,45 & 67,20 & 1.481 .330 & 5.556 .891 \\
2013 & 34,12 & 51,18 & 71,50 & 1.305 .439 & 6.673 .095 \\
2014 & 34,81 & 52,22 & 72,50 & 1.509 .946 & 6.961 .434 \\
\hline
\end{tabular}

Fuente: elaboración propia con datos de Asomicrofinanzas, Banca de las Oportunidades y Banco de la República (2014). 
No obstante, la tasa de usura reflejó una menor relación y explicación con respecto a la bancarización y los segmentos por monto de colocación, lo que permite concluir que esta variable no predice lo suficiente el comportamiento de la inclusión ni de la demanda de recursos (tabla 5).

Finalmente, se encuentra que, en cuanto al número de clientes, esta variable tiene una fuerte relación positiva con las tasas de interés (bancaria y de usura) para el segmento que demandó montos mayores a 25 y hasta 120 SMLV y, en menor medida, con el monto que es menor o igual a $25 \mathrm{SMLV}$. Respecto a la determinación, el comportamiento en el número de clientes tiene mayor explicación por la tasa de interés bancaria que por la usura; sin embargo, la bondad en esta explicación no es lo suficientemente confiable, al ser menor a $95 \%$, lo que indica que hay otras variables que determinan el aumento en el número de clientes y obedecen al orden de las políticas de inclusión social (tabla 6). 

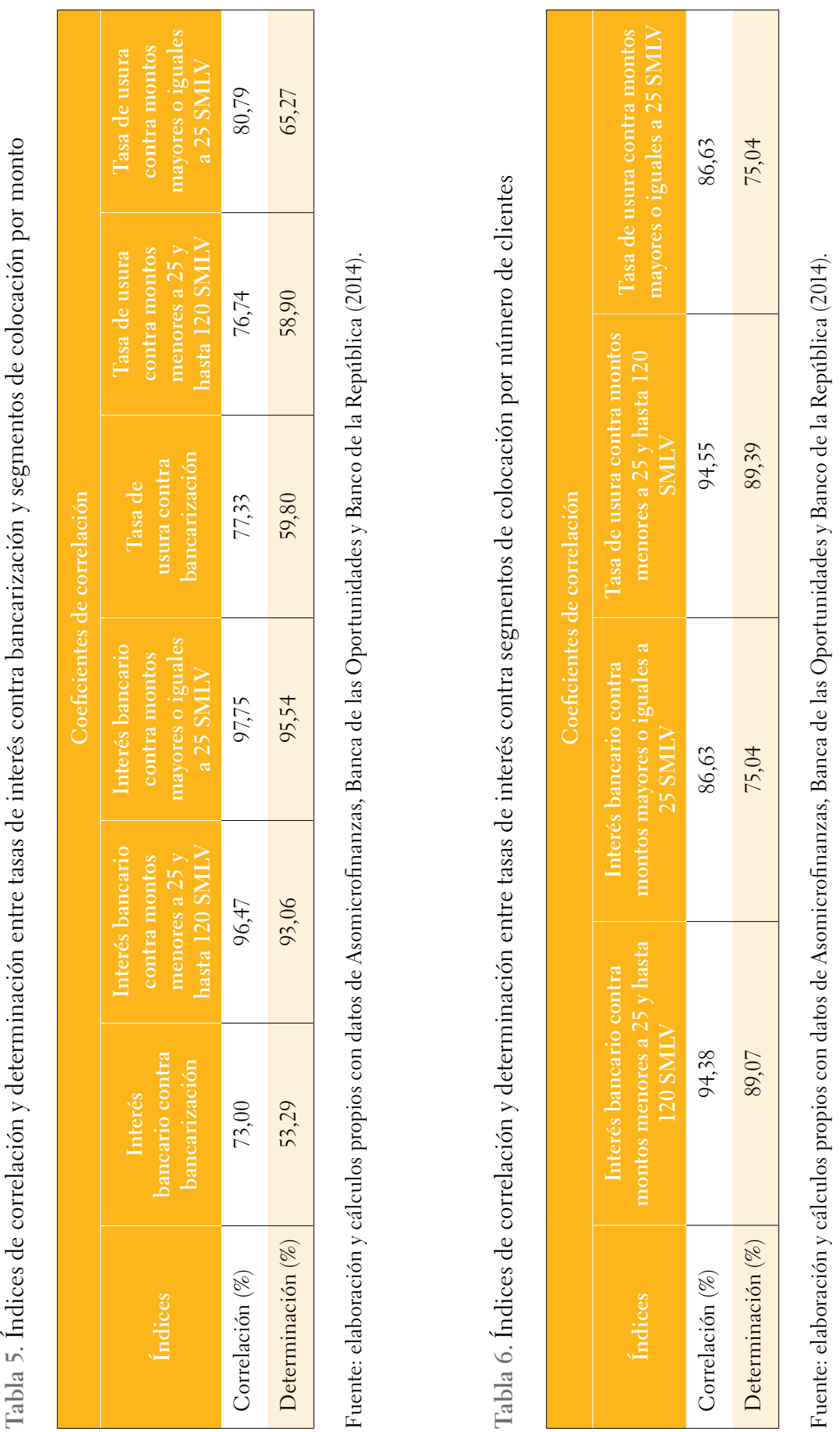


\section{Discusión}

De acuerdo con las escuelas presentadas, se determinó que el modelo de la Escuela de Ohio se asemeja más al modelo de microcrédito en Colombia, en cuanto a que las entidades buscan cubrir las necesidades de los microempresarios que tengan un plan de inversión definido, con experiencia en la actividad económica; repecto a los intereses de los créditos, pocos cuentan con subsdios, esto no permite que se cree una demanda artificial entre los empresarios de mayores ingresos, como lo afirmaba la Escuela.

No se puede descartar que el modelo colombiano de microcrédito no tenga algunas características de la escuela del Grameen Bank, como el planteamiento de estrategias que conducen a la prestación de servicios financieros a los más pobres, ya que Colombia se ha destacado por crear un adecuado sistema que logre cubrir las necesidades financieras de las personas de bajos ingresos; entre otras características en las que se puedan equiparar.

Este sistema es ostensible con el comportamiento durante el periodo 2010 a 2014, donde la demanda de nuevos microcréditos demostró una dinámica creciente tanto en cartera total como en el número de clientes; este crecimiento estuvo respaldado por las diferentes entidades que le apuestan a consolidar sus activos en este segmento, es el caso de bancos especializados, como Bancamia, Fundación WWB, ProCredit, Coopcentral.

En la cartera total, se evidenció una concentración en los créditos inferiores a 25 SMLV (\$15.400.000, al año 2014), con esto se ratifica el crecimiento cuantitativo y, por otro lado, un desarrollo cualitativo por parte de las entidades; la atención de este tipo de clientes requiere un desarrollo en la tecnología crediticia, el mejoramiento 
en los procesos de conocimiento del cliente y la capacitación del personal comercial, debido a que un gran porcentaje de clientes pertenecen al sector informal ${ }^{4}$ de la economía.

240 Por otra parte, en la publicación del Departamento Administrativo Nacional de Estadística (DANE), referente al mercado laboral de Colombia, se afirma: "[de la] población económicamente activa - PEA un total de 22 millones 272 mil personas se encuentran ocupadas para el último trimestre de 2014 [...] de 23 ciudades principales a nivel nacional, con un total de ocupados de 11 millones 960 mil personas, se muestra una tasa de informalidad laboral del 49\%" (Cámara de Comercio de Manizales por Caldas, 2015), es decir, hay una concentración de la población en la informalidad que requiere bancarización y servicios financieros ajustados a sus necesidades.

Para la bancarización de la población con acceso limitado al sistema financiero, las políticas implementadas permitieron ajustar las condiciones del mercado oferente y estimular la inclusión financiera, y se convirtieron en un factor que forjó el crecimiento y el inicio de las oportunidades financieras para las personas de bajos ingresos; según el estudio Microscopio Global 2014, Colombia cuenta con un entorno y con las condiciones propicias para la inclusión financiera, y, junto a Perú, encabezó los puntajes en cuanto a regulación prudencial y reglas para captar depósitos, con un excelente historial en microcrédito (Economist Intelligence Unit, 2014). Colombia se ubicó en el segundo lugar entre 55 países con economías emergentes que garantizaron un entorno propicio para la inclusión financiera.

Una de las políticas más palpable es el Decreto 3078 de 2006, por medio del cual el Gobierno nacional aprobó la creación de la Banca de las Oportunidades, ${ }^{5}$ pro-

\footnotetext{
4 En 1993, en la XV Conferencia Internacional del Trabajo, con el fin de permitir la inclusión del sector informal en el sistema de cuentas nacionales y medir su contribución al PIB de cada país, la Organización Internacional del Trabajo (OIT) definió el sector informal como "un conjunto de unidades dedicadas a la producción de bienes o la prestación de servicios con la finalidad primordial de crear empleos y generar ingresos para las personas que participan en esa actividad. Estas unidades funcionan típicamente en pequeña escala, con una organización rudimentaria, en la que hay muy poca o ninguna distinción entre el trabajo y el capital como factores de producción. Dichas empresas no están registradas bajo las formas específicas de la legislación de cada país, tales como actas comerciales, leyes de seguridad social, etc. y sus empleados no están cubiertos por las normas de la legislación laboral vigentes" (Departamento Administrativo Nacional de Estadística [DANE], 2014).

5 La Banca de las Oportunidades tiene como objetivo promover el acceso a servicios financieros de familias en pobreza, hogares no bancarizados, microempresarios y pequeña empresa (Banca de las Oportunidades, s. f.).
} 
grama de inversión administrado por el Banco de Comercio Exterior Bancóldex, ${ }^{6}$ enfocado en garantizar el acceso a servicios financieros para la población de bajos ingresos, con el fin de estimular el desarrollo económico; principalmente, en el seguimiento a las entidades financieras en cuanto al acceso a crédito, acceso a ahorros, cobertura física, corresponsales bancarios y educación financiera.

La red de la Banca de las Oportunidades está conformada por todas las entidades, como bancos, compañías de financiamiento comercial, cooperativas y ONG, encargadas de prestar los servicios financieros; los resultados de estas entidades, en cuanto a desembolsos de microcréditos desde 2010 a 2014, son 11.273 .584 créditos por un valor de 34,2 billones de pesos; se evidenció la importancia que ha tenido el microcrédito en este periodo y los recursos otorgados a los microempresarios para la inversión en sus actividades económicas, y aunque todavía existe población sin acceso a los servicios financieros, se ha logrado tener servicios inclusivos para la población de bajos ingresos, con una estrecha relación en la bancarización.

Por su parte, la sostenibilidad que ha logrado mantener y los crecimientos tanto en cartera como en clientes destacan la importancia del microcrédito durante 2010 a 2014, y confirman el interés de las entidades financieras por satisfacer las necesidades de las personas, cuyos bajos ingresos provienen de una actividad económica independiente, y que hasta inicios del siglo XX tenían un acceso limitado al sistema financiero.

\section{Conclusiones}

Se reconocen los principales referentes teóricos, planteamientos y aportes expuestos acerca de las microfinanzas, que se han centrado en la inclusión financiera y la disminución de la pobreza por medio del acceso a los servicios financieros. Esto permitió evidenciar que de las dos escuelas presentadas, el modelo de la Escuela de Ohio se asemeja más al modelo colombiano, esto no quiere decir que no haya características compartidas con la escuela del Grameen Bank.

\footnotetext{
6 Bancóldex apoya el financiamiento de las empresas mediante el otorgamiento de créditos por medio de los intermediarios financieros con cupo en Bancóldex, como bancos, corporaciones financieras, compañías de financiamiento comercial, cooperativas financieras, cooperativas de ahorro y crédito, cooperativas multiactivas, fondos de empleados, cajas de compensación y fundaciones especializadas en microcrédito (Bancóldex, s. f.).
} 
Los resultados de este artículo se obtienen a partir de las cifras publicadas por la Banca de las Oportunidades y la Superintendencia Financiera de Colombia, para el periodo analizado; es importante resaltar el progresivo comportamiento del microcrédito, tanto en la cartera total como en el número de clientes, donde se evidenció gran concentración en las operaciones inferiores a 25 SMLV.

$\mathrm{El}$ crecimiento estuvo dado por la oferta de servicios financieros de diferentes entidades financieras, bancos, ONG, compañías de financiamiento y cooperativas; se infiere que las diferentes entidades han mostrado interés para la atención de este segmento, así como la incorporación de nuevos jugadores, que le han apostado a la atención de los microempresarios. Sobresale la contribución de las ONG, las cuales ocuparon el segundo lugar después de los bancos en cuanto a participación de la cartera total.

Se resalta la importancia de los avances en cuanto a las políticas públicas establecidas por el Estado, las cuales se empezaron a adoptar desde inicios del siglo XX en aras de garantizar el acceso a los servicios financieros de las micro-, pequeñas y medianas empresas; una de las políticas que materializó los resultados fue la creación del programa Banca de las Oportunidades, agente encargado de promover y fomentar el acceso a la población de bajos ingresos con el fin de reducir la pobreza y estimular el desarrollo económico.

Los factores mencionados han permitido que el microcrédito de las primeras directrices hacia la atención de los microempresarios, con el objetivo de reducir la pobreza y promover un dinamismo en la economía por medio de los empresarios, busque que estas formalicen sus actividades económicas.

\section{Referencias}

Alcaldía de Bogotá. (2000). Ley 590 de 2000 nivel nacional. Recuperado el 15 de febrero de 2016 de http://www.alcaldiabogota.gov.co/ sisjur/normas/Normal.jsp?i=12672

Alcaldía de Bogotá. (2003). Ley 795 de 2003. Recuperado el 15 de febrero de 2016 de http:// www.alcaldiabogota.gov.co/sisjur/normas/Normal.jsp?i=7850

Asomicrofinanzas. (Septiembre de 2014). Asomicrofinanzas. Recuperado de http:// www.asomicrofinanzas.com.co/images/publicaciones/Boletin\%20No\%2046\%20-\%20 Septiembre\%202014.pdf

Banca de las Oportunidades. (2006). Decreto 3078 de 2006. Recuperado el 15 de febrero de 2016 de http://bancadelasoportunidades. gov.co/es/institucionalidad-para-la-inclusionfinanciera.

Banca de las Oportunidades. (2007). Resolución 01 del 7 de marzo del 2007. Recuperado 
el 15 de febrero de 2016 de http://bancadelasoportunidades.gov.co/sites/default/files/2017-02/ Resolucion-0001-2007.pdf

Banca de las Oportunidades. (2014a). Acceso a crédito. Bogotá. Recuperado el 29 de febrero de 2016 de http://www.bancadelasoportunidades.gov.co/contenido/contenido.aspx?conID $=6$ 90\&catID=300\&pagID=378

Banca de las Oportunidades. (2014b). Quiénes somos. Colombia. Recuperado el 21 de abril de 2016 de http://www.bancadelasoportunidades.com/contenido/contenido. aspx?catID $=298 \& \operatorname{con} I D=673$

Banca de las Oportunidades. (2014c). Saldos de cartera microcrédito. Bogotá. Recuperado en febrero de 2016 de http://www.bancadelasoportunidades.com/contenido/contenido. aspx?catID $=300 \& \operatorname{con} I \mathrm{D}=690$

Banco de la República. (2010). Situación actual del microcrédito en Colombia: características y experiencias. Recuperado el 28 de enero de 2016 de http://www.banrep.gov. co/sites/default/files/publicaciones/archivos/ Temal_sept.pdf

Banco de la República. (2014). Situación actual del microcrédito en Colombia. Bogotá. Recuperado el 31 de marzo de 2016 de http:// www.banrep.gov.co/sites/default/files/publicaciones/archivos/rem_dic_2014.pdf

Bancóldex. (s. f.). Mecanismo de redescuento. Bogotá. Recuperado el 21 de abril de 2016 de https://www.bancoldex.com/Como-opera-Bancoldex307/Mecanismo-de-redescuento329.aspx

Cano, C. (02 de Mayo de 2014). Banco de la República. Recuperado de http://www.banrep. gov.co/sites/default/files/eventos/archivos/ sem_357.pdf

Cámara de Comercio de Manizales por Caldas. (2 de febrero de 2015). Mercado laboral en Colombia: estructura y desafíos. Recuperado el 21 de abril de 2016 de http://www.ccmpc.
org.co/ccm/noticias/?Noti_Id=AwdR2KGlzT6 wB\%2BucHRqyZg\%3D\%3D

Consultative Group to Assist the Poor (CGAP) Portal de Microfinanzas. (s. f.). ¿Qué son las microfinanzas? Recuperado el 27 de diciembre de 2015 de http://www.microfinancegateway. org/es/what-is-microfinance

Departamento Administrativo Nacional de Estadística (DANE). (12 de agosto de 2014). Medición del empleo informal y seguridad social, Colombia. Recuperado el 25 de abril de 2016 de http://www.dane.gov.co/files/investigaciones/boletines/ech/ech_informalidad/ bol_ech_informalidad_abr_jun2014.pdf

Economist Intelligence Unit. (2014). Microscopio global 2014: análisis del entorno para la inclusión financiera. Recuperado el 20 de abril de 2016 de http://idbdocs.iadb.org/wsdocs/getDocument.aspx?DOCNUM=39207371

Gutiérrez, B. (2006). El microcrédito: dos escuelas teóricas y su influencia en las estrategias de lucha contra la pobreza. Ciriec-España, Revista de Economía Pública, Social y Cooperativa, (54), 167-186. Recuperado de http:// www.redalyc.org/articulo.oa?id=17405407

Ocampo, J. (2015). Una historia del sistema financiero colombiano, 1951-2014. Bogotá: El Tiempo Casa Editorial S. A.

Ramírez, E. (2001). Moneda, banca y mercados financieros. Naucalpan de Juárez: Pearson Educación.

Secretaría General de la Alcaldía Mayor de Bogotá D. C. (2000). Ley 590 de 2000 nivel nacional. Recuperado el 17 de enero de 2016 de http://www.alcaldiabogota.gov.co/sisjur/normas/Normal.jsp?i=12672

Superintendencia Financiera de Colombia. (marzo de 2002). Gestión del riesgo de crédito. Bogotá: autor. 
Superintendencia Financiera de Colombia. (2014). Perspectivas de la cartera de crédito. Recuperado el 14 de enero de 2016 de https:// www.superfinanciera.gov.co/descargas?com=in
Yunus, M. (2008). El banquero de los pobres: los microcréditos y la batalla contra la pobreza en el mundo. Barcelona: Paidós. 